Loading

The Journal of the Canadian Game Studies Association

\title{
Fear Thy Neighbour: Socialisation and Isolation in Animal Crossing
}

\section{Miguel Cesar}

Volume 13, Number 22, 2020

Animal Crossing Special Issue

URI: https://id.erudit.org/iderudit/1075265ar

DOI: https://doi.org/10.7202/1075265ar

See table of contents

Publisher(s)

Canadian Game Studies Association

ISSN

1923-2691 (digital)

Explore this journal

Cite this article

Cesar, M. (2020). Fear Thy Neighbour: Socialisation and Isolation in Animal Crossing. Loading, 13(22), 89-108. https://doi.org/10.7202/1075265ar

\section{Article abstract}

In the last three decades Japan has experienced a steady process of social disconnection, the vanishing of interpersonal links, and the decline of the making of new bonds. As an increasingly popular saying, Japan has been labelled as a "muen shakai", a relationless society. Then, while some neoliberal discourses have praised the disappearance of social relationships lionising individualism and self-responsibility, other voices have advocated for the active participation in the making of new communities. This article argues that,Animal Crossing has engaged this debate, exploring the complexities of the process of socialisation, interpersonal relationships, and the making of communitarian bonds. The article further argues that Animal Crossing: New Leaf proposes a socialisation simulation that presents such process as an uncontrollable, unpredictable, and demanding endeavour. To support this argument, the article examines Animal Crossing: New Leaf's main mechanics focusing on its affective design, and how it modulates players' attention through manipulating their agency over the game.
This document is protected by copyright law. Use of the services of Erudit (including reproduction) is subject to its terms and conditions, which can be viewed online.

https://apropos.erudit.org/en/users/policy-on-use/ 


\title{
Fear Thy Neighbour: Socialisation and Isolation in Animal Crossing
}

\author{
Miguel Cesar \\ Independent Researcher \\ miguelcesar90@gmail.com
}

\begin{abstract}
In the last three decades Japan has experienced a steady process of social disconnection, the vanishing of interpersonal links, and the decline of the making of new bonds. Because of this, Japan has been labelled as a "muen shakai", a relationless society. While some neoliberal discourses have celebrated the disappearance of social relationships, lionising individualism and self-responsibility, other voices have advocated for active participation in the making of new communities. This article argues that Animal Crossing has engaged this debate, exploring the complexities of the process of socialisation, interpersonal relationships, and the making of communitarian bonds. This article further argues that Animal Crossing: New Leaf presents a socialisation simulation that presents such a process as an uncontrollable, unpredictable, and demanding endeavour through mechanics that connect the game to the horror genre. To support this argument, this article examines Animal Crossing: New Leaf's main mechanics, focusing on its affective design and how it modulates players' attention through manipulating their agency over the game.
\end{abstract}

\section{Author Keywords}

Japan; Socialisation; Affect; Agency; Isolation; Neoliberalism

In 2012, Nintendo released Animal Crossing: New Leaf, 'Tobidase Dōubutsu no Mori' in Japan. Animal Crossing: New Leaf (AC:NL) is a cheerful representation of interspecies relationships within a small village. The player starts the game travelling on a train to an unknown destination. Sitting in the car they are greeted by an anthropomorphic sweaterwearing cat. The cat is called Rover in the English version, but Mishiranu Neko (Unknown Cat) in the Japanese version. Players are then asked some questions by Rover and it is then that they determine the name of the village they are travelling to, discovering that they are on their way to become Mayor of the little community. It is through this expositional conversation that the player selects their name and gender, as well as the map of the village and its name. The ride comes to an end and they begin their journey.

This paper explores $A C: N L$ as a product of its context, not only as a representation of the worries, hopes, and concerns of contemporary Japan, but also as an experience that aims to have an effect on the players, to speak to them and enact change in the world (Gell, 1998). To do so this article draws from Barbara Rosenwein's (2006) emotional communities to 
90 Loading... The Journal of the Canadian Game Studies Association

Vol 13(22): 89-108

http://loading.gamestudies.ca

argue that $A C: N L$ constructs an emotional community, a social group whose members adhere to the same valuations of emotions and their expression. This article focuses not on the finalised product of an imagined community but rather on the process of constructing a particular community through the tensions and negotiations of game mechanics, and players' agency and control over the fictional world (Eichner, 2013). This process is linked to the complex context of isolation, loneliness and social disconnection of $21^{\text {st }}$ century Japan (Allison, 2013, p. 3). Consequently, this article positions $A C: N L$ as a simulation and a simulacra (Baudrillard, 1981), a proxy to explore the intricacies and complexities of socialisation and making of a community reflecting a landscape of neoliberal prizing of individualism while condemning communalism in Japan. Therefore, this article explores how AC:NL mirrors contemporary Japanese debates about individualism and communalism, and to what extent it challenges these polarised discourses by offering a play experience centred on socialization, community construction, and bonding. Drawing from game design theory (Sicart, 2009), retentional economy (Sitegler, 2010), and affective design (Ash, 2012) I argue that AC:NL is a game that explores the difficulties, fear of, and challenges of socialisation and social relations which are of concern in contemporary Japan. As a muen shakai-a bondless society-various Japanese videogames, including AC:NL, explore how social bonds can be constructed, maintained, and managed, emphasizing their challenges and opportunities (NHK, 2010).

To explore how socialization is constructed and performed in $A C: N L$ this article is structured in two main sections. The first section provides an overview of the main theoretical and methodological frameworks guiding the analysis, and critically reviewing the main debates on bonds, loneliness, and isolation in contemporary Japan. I then proceed to analyse $A C: N L$ using design theory and affective design strategies in relation to the social interactions represented in the game and their outcomes in the gameplay before discussing AC:NL in relation to wider conversations about social construction and communities in contemporary Japan, how the game explores current challenges in a society in crises and the moral and existential proposals it communicates to its players. The paper questions if $A C: N L$ 's simulation is an attempt to teach and prepare players for the world outside the game, or if it capitalises on an increasing number of secluded people that withdraw from society into fictional worlds. Although this paper does not aim to find a final answer for this complex issue, it concludes that $A C: N L$ interrogates neoliberal discourses, based not only on how capitalism impacts materialism and consumerism but also how it has permeated social relations in Contemporary Japan as well as challenges optimistic depictions of community making.

\section{The Social, the Cultural, and the Emotional}

Studies of emotions and affect have been deeply influenced by what has been known in social sciences and humanities as the "emotional turn" (Blackman and Venn, 2010). This section reviews the main concepts in the study of emotions and how they operate affectively in $A C: N L$.

Part of the emotional turn has dealt with the definition and distinction between three terms: feelings, emotions, and affections. The first two seem to be interchangeable in 
91 Loading... The Journal of the Canadian Game Studies Association

Vol 13(22): 89-108

http://loading.gamestudies.ca

ordinary language, however, all emotions connect to certain types of feelings, while not all feelings are emotions, such as feeling hungry, or pain (Burkitt, 2014, p. 5), though they too are highly interconnected to the physical, as they give us a sense of embodied relation to the world (Cromby, 2007, p. 102). Feelings and emotions are, therefore, bodily forms of perceiving the world, but it is social meaning that distinguishes feeling from emotion (Burkitt, 2014, p. 5). As John Dewey (1958) argues: emotions are not experienced as such initially, but depend on retrospective awareness of a situation. An emotion gets defined as such in terms of its social meaning and contextual relation to others.

Meanwhile, 'affect' has two meanings. The first links affect with 'having an effect on'. That is to say, being changed by a feeling or emotion in relation to something or someone, the affected one is then moved from one state to another (Burkitt, 2014, p. 6). The second meaning stresses the human ability to enable a particular emotion to have an effect on others. Emotions are then affected according to the scenario; however, this only occurs once we have learned how to produce emotions under certain situations. Affect, therefore, is part of a process of learning and teaching and, according to the third meaning, an emotion or desire that influences behaviour. It is, according to psychological approaches, a cognitive means for processing information (Duncan \& Barrett, 2007). In summary, affect refers to any state that represents how an object or situation impacts a person (Duncan \& Barrett, 2007, p. 1185).

Affect is also central to the understanding of how information is narrativized and perceived (Massumi 1995, p. 88). Affect varies, and it is quantified based on intensity, including its social elements (Massumi 1995, p. 91). These elements come from a postmodern reading of late capitalism and a state of depthless, flat contemporary culture (Eagleton 1996, p vii). Furthermore, affect refers to interaction and the existential process of becoming, an intensive force that all bodies exert upon each other. This, for Massumi, does not only include human bodies, but also non-human. Therefore, computer games such as $A C: N L$ influence the relationship between players as well as between players and NPCs. Therefore I, as Aubrey Anable (2018), pay attention to the representation of emotional labour in AC:NL. Affect here, and building on Massumi (2002), becomes tied to subjects such as fear, happiness, love, sorrow becoming representable and observable. Thus, affect becomes readable, traceable as procedures, images, mechanics, and rhetorics, being part of larger systems of labour, belonging, representation, etc.

This terminological clarification is relevant for this exploration of emotions and affections in $A C: N L$ since the importance of both terms have evolved in recent approaches to cultural studies. In the last 10 years the 'turn to emotion' has developed into the 'turn to affect' (Blackman \& Venn, 2010). In cultural studies the term affect is about the intensity of experience rather than the quality of the emotion associated with it, or the discursive forms through which it is represented. Affection is that which relates to the body rather than the conscious mind. Thus, concerned with the flow of intensities circulating between bodies, affect escapes all attempts to articulate it. Affect is non-rational and accounts for the forces that can grip whole communities (Seigworth \& Gregg 2010, p. 1). But then, as it is not separated by bodies, it is neither a mystical force, but a material process of its own kind created by body-selves acting in relational concert (Burkitt, 2014, p. 8). We, therefore, 
92 Loading... The Journal of the Canadian Game Studies Association

Vol 13(22): 89-108

http://loading.gamestudies.ca

cannot separate affect from the corporeal or the discursive. Language itself belongs to the realm of abstract linguistic rules, a practice learned and applied (Merleau-Ponty, 2012, p. 425). The corporeal is even more relevant considering the complexity of virtual and digital experiences due to additional aspects such as avatar embodiment, ludic environment and the responsive mediality of the computer game (Delamare, 2011, p. 239).

Thus, this article follows what Ian Burkitt calls an 'aesthetic understanding of emotion' (2014) which explores how humans make and experience meaning, and how the body is a fundamental element in this process (Johnson, 2007). Our feelings and emotions being the means by which we orientate ourselves in particular situations and in relation to others, we develop ways of responding emotionally to specific contexts, creating a net or patterns of relationships and actions open to change (Burkitt, 2014, p. 6). This article investigates the adjustment, change, and fluidity required of $A C: N L$ players to emotionally interpret and react to one of the central challenges of the game: to be social, to understand the net of emotions and emotional signs in the game, and to exercise affection.

This comes from the understanding of the computer games as affective systems that talk about contemporary culture, distinct from other media (Anable, 2018). It thus draws from affective design, an approach to how video games are designed to modulate and amplify the affective impact of the experience of playing them. Affect then expands how video games work as media, culture, and ideology, on us, including our feelings and identities. Affect is the capacity to act and be acted upon, a key characteristic of how computer games work and what they are. Affect flows between people and cultural objects (Ngai, 2005).

To better comprehend how AC:NL designs its affect fluctuations we need to understand the current emotional liquidity of Japan as a heterogeneous and shifting community.

\section{Isolation, Loneliness, and Community in Liquid Japan}

On January 31, 2010 the Nippon Hōsō Kyōkai (Japan Broadcasting Corporation) released a documentary labelling Japan as a muen shakai "relationless society" (Allison, 2015). After a decade of economic, political, and sociocultural crises, Japan was perceived as a country where its people were living in increasing isolation. The Nippon Hōsō Kyōkai (NHK) used the phenomenon of the "lonely death" as its iconic example as thirty-two thousand Japanese died alone at home in 2009. The figures of the documentary showed a deeply troubled society with one-third of the population living without company, the rate of childbirth steadily decreasing, the number of marrying couples declining, and overall, a generalised feeling of a population uninterested, afraid, or incapable of forming social bonds. But how did Postwar Japan, a country of incredible successes, shift from a national state of lifelong attachments and belonging into a liquefied Japan where everything economic, social and cultural is unsure, fluid, and vanishing (Gordon, 1993)?

In 1991 the economic bubble Japan had fostered during the 1980s burst. Stagnation and recession set in and companies began to restructure, merge, downsize or disappear (Kingston, 2010, p. 24). In this context of economic crisis youths were particularly hard hit, becoming the "lost generation" in the first of Japan's "Lost Decades" (Allison, 2013, p. 29). 
93 Loading... The Journal of the Canadian Game Studies Association

Vol 13(22): 89-108

http://loading.gamestudies.ca

Furthermore, the destruction of the work-place and its space for socialisation put an end to Japan's dependency culture, built and sustained during the Postwar decades on two pillars: family and corporate belonging (Allison, 1994). While men socialised within the company women and children did it at home, as an ecosystem of knitted affect, care, duty, and belonging (Nakane, 1967). Thus, human attachments and bonds were structured around differentiation and hierarchy, defining every social relationship. Family from the household was transferred to the workplace as well as the affect of dependence (amae) (Takeo, 2001).

However, by the end of the Lost Decade Japan's dependency culture had lost its profitability and advantage for the big corporations and the conservative governments. Seen as a burden for economic development and companies' competitiveness, neoliberal ideologists advocated for and initiated its dismantling. But the accusations went deeper as these reformers blamed the dependency culture for creating unhealthy "interdependent relationships that hinder individuals from exercising initiative and developing entrepreneurship" (Takeda 2008, p. 156). The so-called "Iron Triangle" of the Liberal Democratic Party (LDP), bureaucrats, and big corporations that has played a central role in the institutionalisation of the idea of a middle-class country (Chiavacci, 2008, p. 6) raised a new banner of "risk and individual responsibility" (risuku to jiko sekinin) (Allison, 2013, p. 28). Under this new narrative the government asked its citizens to become strong and independent individuals "capable of bearing the heavy weight of freedom" (as cited in Miyazaki, 2010, p. 243).

Nevertheless, the interdependencies and bonds that once tied Japanese society together were now undone or deeply diminished, leaving many people unprotected, adrift, and hopeless. During the 1990s the middle-class country and stable society that Japan was once thought to be turned to a general sense of malaise, unsureness, and existential anxiety (Giddens, 1991). This state endured, and a decade later the same trends have persisted. With the economy showing no signs of improvement new crises spread across the country. In 1995, a 7.2 on the Richter scale earthquake devastated the city of Kobe causing 6,200 deaths. Almost a third of the whole city was destroyed leaving thousands of families homeless (Iida, 2000). A year later a group of the religious cult Aum Shinrikyō committed a series of indiscriminate attacks in Tokyo's underground train using sarin gas, killing and injuring more than 5,000 people (Iida, 2000, p. 426; Kingston, 2010, p. 29). The news spread across the country, deeply harming the myth of Japan's internal security and increasing the sense of a nation in collapse. Furthermore, two years later, the country was shook by the "Young A" murders. The "Young A" of Kobe was a case in which a 14-year-old boy committed a series of attempted murders and two successful murders (Iida, 2000). The boy, coming from what was considered to be a middle-class ordinary family blamed in his confession note the education system, his family, and the adult world that has turned him transparent (Iida, 2005, p. 234). Consequently, as Anne Allison (2013) argues, "the very fabric of everyday life at the turn of the twenty-first century seemed to be getting ripped asunder" (Allison, 2013, p. 30). This social malaise has hit the youth hardest of all, leading in the figure of the hikkikomori.

Hikikomori are mostly young adult men in their teens or twenties who decide to seclude themselves in their rooms for months or years (Hairston 2010, p. 311). They have 
94 Loading... The Journal of the Canadian Game Studies Association

Vol 13(22): 89-108

http://loading.gamestudies.ca

developed a fear of social interaction with the outside world, deciding to stay in their rooms, (Kotler, Sugawara \& Yamada 2007, p. 112). Hikikomori withdraw from physical contact with any other person, even their family in the most extreme cases (Hairston, 2010, p. 311). Hikikomori also tend to quit school and have no job. This group has also presented a challenge for mental health professionals since the awareness of this new phenomenon became indisputable (Teo, 2010, p. 178). Although the number of Hikikomori has risen to $1 \%$ of the Japanese population (Todd, 2010, p. 135), there is the suspicion that an undetermined but higher number of cases have not been reported yet due to shame and overprotection (Malagon et al. 2010, p. 558; Teo, 2010, p. 181).

The following decade of 2000-2010 saw an increase in the general uneasiness of the nation. As the main challenges that Japan was disregarded by the main institutions, news of economic collapse, societal disconnection, and cultural shifts further permeated everyday life (Allison, 2015, p. 2). Human connections led to family dissolution, the increase of the hikikomori, and a sense of a tortured existence steadily manifested through popular media shows, manga, anime, and computer games (Cesar, 2020). Things would only get worse.

In the summer of 2008 isolated, random, and public acts of violence plagued Tokyo. The perpetrators resorted to violence to express their frustration and anxiety with a world in which they had no place. The violence was impersonal, as random attacks on strangers by disconnected individuals manifested not only on the streets, but also within households. Especially shocking were recurring accounts of children turned against their parents and, in some cases, through macabre mutilations of their family's bodies (Allison, 2015, p. 4). In all these cases, however, the causes seems to be same: disconnection, lack or inability to communicate, existential anxiety and frustration.

A great part of this suffering comes, however, not only from incapable or uninterested institutions, but through abstract socioeconomic and cultural systems. Everywhere people suffer from the inequalities, instabilities, and unsureness of unregulated neoliberal globalisation. In a liquid economy were everything is abstract and hyperreal (lacking content but not form) (Baudrillard 1981) the failure to cope with everyday life is a recurrent experience. But the case of Japan, despite its apparent wealth, shows signs of extensive precarity. Japan has the second highest level of poverty among the Organisation for Economic Co-operation and Development. The country has a rate of $15.3 \%$ of people who fall below half of the mean income. Furthermore, one third of all workers are irregularly employed, lacking economic stability and benefits (Allison, 2015, p. 5). This situation is even worse for women and youths, as half of them and $70 \%$ of female workers are only irregularly employed (Yuasa, 2008).

Politically the country is in a transition from a miraculous recovery to an economy in decline, if not collapsed. Changes are also taking place in the body politic from a vast middle-class society (although limited (Chiavacci, 2008)) to a polarised, downstreaming one. Poverty is, however, more than just material deprivation, as it entails a state of panic over debt and rent, desperation, a life on the edge while hope has become a luxury and the future has turned bleak or unreachable (Yuasa, 2008). Furthermore, material precarity also permeates other dimensions as human condition becomes a precarious existential 
95 Loading... The Journal of the Canadian Game Studies Association

Vol 13(22): 89-108

http://loading.gamestudies.ca

state (Lazzarato, 2004). Especially in Japan, individuals depend on their jobs to maintain a stable knot of dependencies, attachments, social relationships, and connections, as it is around your company that you build your human interactions and interpersonal relationships. As Judith Butler puts it "precariousness implies living socially... one's life is always in some sense in the hands of the other" (Butler, 2009, p. 14). Precarity is dependency, obligations, and uncertainty. Life becomes unsure, unstable, liquid (Bauman, 2000).

This existential anxiety has been captured by activist Amamiya Karin's izikurasa (pains and difficulties of life), a word that captures the sensory nature of living in the precarity of contemporary Japan. As social living becomes more painful it alienates the human from "its body and soul" (Berardi, 2009, p. 22). Alienation spreads as estrangement from capitalistic interest, as izukarasa deals with alienation between time and capitalist value while it leads to further alienation from society and others (Allison, 2015, p. 18). However, at the same time there are signs of new struggles to make a Japan where fewer are subject to precarity. This manifests through attempts to create different attachments and alliances, new forms of social ways and connections, and further existential revaluations in which popular culture and media might play a key role through their procedures, rhetoric, and discourses (Murray, 2016; Bogost, 2007).

In that deeply troubled context, bonding creating links, and connecting to people became a difficult and uncertain struggle. This increased a deep state of ontological insecurity that manifested in the lowest childbirth in years (1.34\%), a decline of the population, and the number of suicides steadily increasing for more than a decade (Allison, 2006; Allison, 2013, p. 30). In that landscape, different discourses lionised the individualistic enterprise praised by neoliberal ideologists. Self-help books, TV dramas, and a whole literature on how to become independent and self-sufficient taught the benefits of learning to happily living alone. This literature, however, contrasts with more than a decade of intermedial discourses warning about the vanishing of society, the pain from the disappearance of social connections, and the dangers of isolation and loneliness.

This was the main concern of the creator of the Animal Crossing franchise and current producer of the series, Eguchi Katsuya. In 1986 Eguchi graduated from a computer graphics course from Chiba, north of Tokyo (Edge, 2008). As suggested by his friend he decided to apply for a job at Nintendo, moving to Kyoto where the company has its headquarters, hundreds of miles from Eguchi's home. There, Eguchi spent the first years fighting loneliness, away from his friends and family and in a strange city. As Eguchi (2001) describes the creation of Animal Crossing as "a result of being so lonely when I arrived in Kyoto! Chiba is east of Tokyo and quite a distance from Kyoto, and when I moved there I left my family and friends behind" (Eguchi, 2001).

This feeling of social disconnection persisted even as Eguchi formed a family in Kyoto. After working long hours, he would come home late at night. He and his family, Eguchi says, played games but rarely did it together. As he noted in another interview "it would be nice to have a play experience where... we are still sharing things together" to close up by 
96 Loading... The Journal of the Canadian Game Studies Association

Vol 13(22): 89-108

http://loading.gamestudies.ca

remarking that "it was a kind of desire to create a space where my family and I could interact more, even if we weren't playing together" (Sheffield, 2006).

Therefore, Animal Crossing's original idea according to its creator had three main themes at its core: "family, friendship, and community" (Edge, 2008). And there are direct references in the game to Eguchi's experience when moving to Kyoto. As Eguchi was, the players are strangers in a strange land, delivered by taxi or train, bearing few possessions, with no friends or acquaintances in this new town, having only their job there to identify with. Isolation is, therefore, only transformed and turned into companionship through active socialisation and community making. Players are then motivated not only to take part in social activities but also to become a central piece in the making of the group, the collective. And this, while a recurrent theme in contemporary Japanese popular culture media, has cultural, social, and political connotations in a context of communitarian disintegration and the vanishing of bonds and relationships. But Eguchi's games are more than a socialisation simulation, they are a challenge to the process of making bonds, of constructing interpersonal relationships, and an exploration of the complexities of these interactions.

To do this AC:NL draws from different mechanics for its affective design. One of its main tools while examining social connectivity is the fluctuation, manipulation and illusion of agency and player control. This connects to the empowerment and disempowerment of individuals while it modulates affect and attention by restricting the players' abilities to act and transform the world. Thus, on the one hand it grants the freedom to roam the village and its surroundings, to interact or not with the different characters, and to choose between the different options it allows. But, at the same time, $A C: N L$ presents only possibilities that are limited and tied to the game's specific interpretations of how society is or could be. This article argues that in $A C: N L$ the choices put before the player are not only limited but also limiting, made restrictive to manifest the actual constrains of socialization in the world outside the game. AC:NL is also something of a dystopia, one that, behind its apparent cuteness and innocence, hides disturbing capitalist dimensions, social conflict, and negotiations of cultural boundaries. AC:NL challenges in promising ways the concept of agency and its ties to neoliberalism by limiting the players' agency, toying with their expectations of the seemingly adorable world in front of them, and the reality of social relations (Jameson, 1991). But it also maintains stereotypes, structures of power, and established neoliberal cosmologies.

Thus, it is in this contested ecosystem that Animal Crossing stands as a game that aims to motivate players to experience being social, the challenges of forming bonds, and manifests the complexities of connecting. The game is designed to encourage players through its procedural rhetoric, the rules and processes that embody AC: NL's representation of how the world works, challenging the players to operate in it (Murray, 2016; Bogost, 2007).

Procedural rhetoric is a term that combines two main concepts, procedure (the computer's ability to execute a series of orders) (Murray, 2016, p. 71), and rhetoric. Procedural systems generate behaviours from rule-based models based on the coded procedures that computers use to represent real or imagined systems, worlds, values and structures (Bogost, 2007, p. 5). These rules are also cultural, crafted from intersecting cultural 
97 Loading... The Journal of the Canadian Game Studies Association

Vol 13(22): 89-108

http://loading.gamestudies.ca

processes, categories, and cosmologies as well as the premises that inform the logic of the videogame. Visual, verbal, and behavioural procedures are all based on the authors' and designers' conceptions of the world, and depend on their intentional inclusion or exclusion of certain ideals and values. These are then expressed and communicated to the players through the rhetoric of the procedures, the mechanics, structures, and rules of the game. Rhetoric, that second concept, refers to public speaking, to persuade as well as to communicate. Thus, procedural rhetoric refers to "the practice of using processes persuasively" (Bogost, 2007, p. 28). The term thus entails persuasion, to convince through effective expression, communication that is performed through rules of behaviour and the construction of dynamic models through code and programming. These provide new ways of representing, communicating, and negotiating values, sociocultural structures, ideals, and cosmologies. But for the procedures and the rhetorical exercise to convince the players, to engage them and make them take part in the procedural world the computer game creates, the design has to be persuasive, not only convincing.

The following section focuses not only on the social simulation and simulacra $A C: N L$ creates, but also how it persuades players to accept that world, to normalise it or challenge it, and to participate in it. $A C: N L$ comes from a context that it both reproduces and interrogates, a context of a "relationless society". To comprehend how AC:NL constructs, through its gameplay, that challenge to neoliberal discourses on loneliness, isolation, and social disconnection, the next section examines the game's mechanics, and how it is designed as an experience focused on existence within, at the margins, or outside a community.

\section{Fighting Loneliness: The Pedagogy of Being Social}

In her 2006 book Emotional Communities in the Early Middle Ages, Barbara Rosenwein defines emotional communities as "groups in which people adhere to the same norms of emotional expression and value -or devalue- the same or related emotions" (Rosenwein, 2006, p. 2). Rosenwein further argues that these communities change over time and that many exist within the same context, some easier to trace than others. This section builds from this concept of emotional communities to examine $A C$ : $N L$ 's mechanics and how they modulate players' control over the social process the game proposes. This modulation is performed in AC:NL through what James Ash defines as "affective design" (Ash, 2012). Affective design develops from the study of the transmission of knowledge through the relationship between affect and attention of human memory (Stiegler, 2010). In game design studies affective design focuses on the techniques used to captivate and manipulate attention, emotions, and construct affect (Thrift, 2006, p. 286; Berlant 2008; Featherstone, 2010). In the case of $A C: N L$, a major mechanic variation has to do with agency fluctuation and the control players have over the dialogues and their social connections. Agency, and its modulation, becomes a central point of attention as AC:NL and its depiction of interpersonal relationships as unpredictable, uncontrollable, and even in some cases, strange and uneasy. Consequently, this section examines how AC:NL designs these social connections within its game world and relates it to its engagement with Japanese contemporary conversations on individualism, loneliness, isolation, and communalism. 
98 Loading... The Journal of the Canadian Game Studies Association

Vol 13(22): 89-108

http://loading.gamestudies.ca

In his 2007 book, Ian Bogost defined Animal Crossing as a "village simulator" (Bogost, 2007, p. 267). The players move into a town filled with aesthetically cartoonish animal NPCs (Non-Playable Characters) where they buy a house, work, trade, and personalize their microenvironment (Bogost, 2007, p. 267). The game offers a series of activities including some mundane chores such as gardening, fruit gathering, bug catching as well as socialization opportunities such as chatting with the neighbours, doing errands for them or helping them with their connections and relationships to others.

Academic literature on Animal Crossing has mainly focused on its depiction of late capitalist economies and societies, and how they affect individuals' lives (Bogost, 2007; Brown \& Marklund, 2015; Kim, 2015). Part of AC:NL mechanics are centred around the social interactions between players and their animal neighbours. Thus, although the players might avoid talking to the village inhabitants they have to converse with the owners of the different shops, their secretary, and many other characters. These relationships, however, are also deeply influenced by the game's consumerist mechanics. In this regard, Bogost has used the term affluenza to discuss AC:NL mechanics (Bogost, 2007, p. 268). The term affluenza refers to the spiritual emptiness and guilt which accompanies wealth and the feverish drive to acquire more debt and material property, an emotion that affects all social classes (de Graaf 2005, p. vxi). In this late capitalist society, shopping and consumption becomes a cultural practice, as well as a contributor to rising debt and bankruptcy. This is a structuring and central mechanic of $A C: N L$ that simulates and examines the condition of affluenza. Right at the start of the game, players begin with significant debt from the house that has been constructed for them. Paying off that debt is the only way for players to expand their house, which the game repeatedly suggests they do. As the players pay their debt and expand their houses Tom Nook, the shopkeeper who manages the real estate business, closes his shop and upgrades it until it becomes a two-story department store. The players might pursue the expansions of their houses to also expand Tom Nook's supermarket to get access to more material consumables from which to choose (Bogost, 2007, p. 269). This creates a consumerist loop. But AC:NL's relationship to consumption is ambiguous and does not force the players to pay their debts, to expand their houses, or to buy new things (Kim, 2015). Consumerism and materialism are a luring temptation, but not a mandatory victory condition, as the game lacks any immediate or long-term objectives.

On the other hand, as Eguchi, Animal Crossing's creator has explained, $A C: N L$ is a game focused on the construction of emotional communities, how they are maintained and the challenges of belonging. To emphasise this feature the game is mechanically designed to have quick actions that require few inputs (Brown \& Marklund 2014, p. 7). For instance, selling an item to the store owner requires only 13 inputs, with more than half based on the dialogue. This design makes some interactions fast and easy with dialogues that sometimes repeat information. However, some conversations introduce new information about the NPCs, their personalities, hopes, and concerns, requiring closer attention from the players. Thus, these interactions between players and NPCs become the only channel through which players get to know and understand their neighbours. In other words, conversations fluctuate from standard small talk to more intimate and extended dialogues. Therefore, as a franchise released at the beginning of the Second Lost Decade (2000-2010) in Japan, AC:NL proposes a socialising sandbox that teaches and explores the challenge of bond making and 
99 Loading... The Journal of the Canadian Game Studies Association

Vol 13(22): 89-108

http://loading.gamestudies.ca

the external world, a mechanic that has to do with players' agency and its limitations within the game. I will thus examine how the fluctuation of players' control is designed in $A C: N L$, and how this affective modulation works within its world.

There are two main mechanics in AC: $N L$ related to the socialisation process and building of interpersonal relationships within the game. Both mechanics have to do with how agency and control are manipulated and fluctuate to increase the challenging project of being social. The first of these mechanics is what Nicolas Fortugno calls 'futile interaction'. This concept refers to scenes in which the players are given agency with a task that seems accomplishable despite being designed to be mechanically impossible (Fortugno, 2009, p. 176). In these scenes the players have control over their avatars, but not over the outcome of the scene, which is already decided. This is a recurrent mechanic in $A C: N L$ interactions with the inhabitants of the village. For instance, fake choices abound in the game and are a central mechanic in socialisation in AC:NL. One of the most representative examples is analysed by Brown and Marklund (2014) as part of the construction of the uncanny and oppressive in AC:NL. In their study, Brown and Marklund argue that, despite AC:NL not being a horror game, it contains elements of that genre by constructing situations of tension and terror while socializing with the NPCs. For instance, the concept of limited and blind agency in the game reinforces the alienation of the players, a recurrent trope of horror games to evoke feelings of loss of control and powerlessness (Rouse ,2009; van Elferen, 2015). The constraint in the dialogues, a central mechanic of $A C: N L$, is a powerful tool to obscure the agency and control of the players over the game and their options in its world (Brown \& Marklund 2014, 1p. 4). Consequently, the game constructs interpersonal relationships as complex, challenging, and often uncontrollable. In this way, $A C: N L$ explores, through its mechanics, how terrifying society and individuals can be, how challenging making bonds and interactions can become, and how we should react, meditate on, and deal with them. I now turn to illustrate this design by exploring it through some examples.

One of the most recurrent and representative situations of futile interaction while being social in $A C: N L$ occurs when visiting the coffee shop. There we meet Brewster, a moustached pigeon barista who works there. After ordering a coffee, Brewster asks the player if they will drink the coffee immediately or wait to let it cool off. However, whether players decide to wait or not has no consequences as they are forced to drink the coffee right away and get reprimanded. This false choice reinforces the illusion of player agency and control over a game that, ultimately, bluntly controls the players' options and exercises its power over them.

Futile interaction has an impact on the affective design of the game and it is aimed as a challenge to the players' experience of $A C: N L$ 's apparent friendly and light-hearted ecosystem. Futile interaction is, nonetheless, not only a recurrent mechanic with narrative consequences but also a structuring dramatic tension of how $A C$ : $N L$ represents social relationships. In the game, social bonding and interpersonal relationships are experiences of futility, agency fluctuation, and disempowerment as their neighbours act as uncontrollable and unpredictable agents that often act independently from players' intentions. Thus, futile interaction contrasts and challenges assumptions on the 
100 Loading... The Journal of the Canadian Game Studies Association

Vol 13(22): 89-108

http://loading.gamestudies.ca

democratisation and liberating potential of video games due to interactivity and its democratisation of participation (Cover, 2004, 1p. 74; Kim, 2014, p. 357). As some authors grow weary of the limitations of interactivity in games that create a sense of freedom and empowerment (Behrenshausen, 2013), AC:NL actively constrains agency and players' control and draws their attention to those moments beyond their power. Furthermore, while Andrejevic (Andrejevic, 2009, p. 35) argues the democratizing power of interactivity has coincided with increasing political and economic inequality, $A C: N L$ proposes a mimetic representation of the asymmetry of power relationships and the lack of control of individuals in a challenging landscape.

This type of interaction is labelled by Brown and Marklund (2014) as 'blind agency', a concept that is commonly applied in literature studying horror games. Its use in the horror genre of video games aims to inspire terror and fear by limiting or taking away the players' agency in specific situations (Rouse, 2009; Perron, 2009). However, to use this mechanic in a friendly game such as $A C: N L$ is more striking, and its motivations harder to comprehend. Nonetheless, horror, lack of agency, and isolation are recurrent tropes in contemporary Japanese discourses (Napier, 1996; Hughes, 2000; Cesar, 2019). This is not only a manifestation from the sociocultural landscape of the Lost Decades, but also part of its polyphonic intertextuality. In other words, these are texts that originate from a context which they influence in turn. Works from visual popular culture recurrently narrate a general malaise and concern about isolation, social disintegration, and the uncontrollability of everyday life (Inoue, 2012; Perkins, 2012). Thus, the horror genre has been frequently used in Japan to examine the social breakdown of the times by, for instance, disturbing the pattern of everyday life and challenging the audience's expectations (Allison, 2013, p. 113). Horror then subverts the ordinariness where human identity resides (Asad, 2007, p. 71) as in films by Kurosawa Kiyoshi such as Cure, Pulse or Tokyo Sonata, or Kitano Takeshi's Battle Royale or animated series as Kon Satoshi's Paranoia Agent.

Furthermore, $A C: N L$ implements futile interaction and blind agency to manipulate players' affection by giving restricted options while interacting with the neighbours. Given that social bonding is a key feature of the game's experience, the design of casual conversations and everyday socialisation is relevant, for it determines the game's approach to teaching and depicting interpersonal relationships. In this regard, most of the conversations between players and NPCs commonly present two options: continue the conversation or end it by saying "goodbye". These formulaic responses limit and restrict the players' options and subsequent control over their relationships, how to form, manage, and maintain them. Nevertheless, even in the most rudimentary conversations there is often an uncanny and unsettling tone (Brown \& Marklund 2014, p. 7). These trends do not always relate to previously negative encounters or history between players and NPCs. Sometimes the NPC is upset, distrustful, sad or angry and there is no way to change it, to have any impact over the situation. This increases the limitation of the players' control over the game beyond their avatar, a fluctuation of agency typical of the horror genre, which uses this trope to convey a sense of disempowerment (Rouse, 2009). This limitation of agency, and especially its changes when the game restricts it, increases tension and the feeling of vulnerability in players (van Elferen, 2015). Consequently, $A C: N L$ depicts social structure and interpersonal relationships as a site to feel exposed, at the mercy of others. Although 
101 Loading... The Journal of the Canadian Game Studies Association

Vol 13(22): 89-108

http://loading.gamestudies.ca

some have postulated that it is interactivity, agency, and players' empowerment through different models, it is the manipulation of the quintessential mode of computer games that constitutes $A C$ : $N L$ 's key interpretation of social relationships. Thus, despite models such as Information and Communication Technology (ICT) that praise the support of players' agency and autonomy (Zhang, 2008, p. 147), their restriction is just as effective to modulate affect, through attention and control over the game world and its inhabitants.

There is, however, a second dimension of $A C: N L$ 's social simulation experience: the online multiplayer. While the online experience differs from the relationships and interactions to the NPCs, as online avatars are controlled by actual players, it reinforces the original plan of Eguchi of being able to connect with his friends and family as well as problematises the aim and intention of the game. In the game, once you are connected with another player you may walk around in your town or visit the other player's in-game home. Players can do almost anything they could do in solo mode, but now with a friend. This is, therefore, a quite limited feature. As such, connectivity, and social interpersonal relationships are limited by the game's content, world, and structure. Other avatars are, however, like the NPCs, uncontrollable, unpredictable and sometimes challenging.

This leads back to the main interrogation of this paper: does $A C: N L$ create a world that teaches players how to operate in the social world outside the game? Or does it construct a compelling world to take advantage of the social disconnections of Japan? Could it be both? $A C: N L$ is a game that does not so much criticis but simulates capitalist, consumerist societies. This works in the logic of highly capitalist societies, characterised not by the making of products, but the making of worlds (Lazzarato, 2004, p. 96). Capitalist value comes from that process of creating worlds, other platforms of existence (Steinberg, 2019, p. 4). And this is done through narrative, as it produces desires in an era when use and sign value have lost their interest (Fukuda, 1990, p 60). And narrative is so successful "because it is a fundamental part of human experience" (Steinberg, 2019, p. 60). In the online multiplayer of $A C: N L$, players get to share their narratives with others as well as to participate in theirs. Narrative is a consumable that gets enjoyed through sharing and communication. The platform, in this case $A C: N L$, is the place where money (real and fictional), people, and communities meet.

On top of that, to give life to these worlds and ensure their functioning, they were populated with stories. As marketers looked for new ways to engage customers and maintain or increase sales, they created needs based not just on isolated signs and symbols, but on overarching narratives that made sense of them (Steinberg, 2019, p. 59). Consumables were supposed to have and construct a narrative, to tell a story. which has direct impact on the online multiplayer of $A C: N L$. As players visit each other's towns they get to experience and witness the narrative of a different town. And town development and players' reforms on their houses are part of a story built on consumption and expenditure. For instance, visiting a house full of luxurious goods might lead another player to try to replicate it, compete, or build a counter-narrative of it, reproducing the flow of consumption of the game, and of goods that exist within it.

But all these mechanics that construct a social simulation that imitates part of that "raw human part" that Sherry Tarkle (2011) argues has been lost. $A C: N L$ might replicate life in 
102 Loading... The Journal of the Canadian Game Studies Association

Vol 13(22): 89-108

http://loading.gamestudies.ca

order to teach players how to be more social or to keep them consuming the game. Either way, this is a highly successful series, one that has become a keystone for Nintendo. Such a positive result proves that, even within the virtual fictional world of computer games, people crave interpersonal interactions, and the uncomfortable unpredictability of being powerless, but social.

Thus, the fear of others and subsequent social withdrawal are widespread phenomena of the Lost Decades and a recurrent theme explored by Japanese visual popular media (Allison, 2013, p. 153). Nonetheless, as fewer feel safe, as fear of society increases, so does dissatisfaction with the cultural status quo, and many start to look for their own voices to discuss, debate, and face the challenge of a vanishing community. Increasingly, more Japanese advocate for the creation of a new society, one where everyone takes care of everyone and individualism is not a synonym of selfishness and egocentrism. In that convulsed ideological polyphony $A C: N L$ stands as a challenging examination of community construction and its complexities, and as an exploration of humans as social beings.

\section{Conclusion}

To be actively social in $21^{\text {st }}$ century Japan is not a neutral choice - it is part of a political endeavour, and it has political consequences. Building social interpersonal -or even interspecies- relationships and bonds has been challenged and attacked since the end of Japan's First Lost Decade by neoliberal reformers and ideologists (Takeda, 2008, 156; Allison, 2015). In that context, the neoliberal narrative was not only aiming to attack and dismantle communitarian bonds, but also to put the blame and responsibility for the country's failure on the individuals. The government, companies, banks, and the oligarchic establishment exhibit no accountability for the rampant crises as they externalize blame and cast it onto others.

This is a recurrent theme in neoliberal rhetoric, one which different discourses and media reinforce (Jameson, 1991; Rouse, 1999, p. 87; Muriel \& Crawford 2018, p. 3). One such medium is video games, and they do that through their immersion and agency. This feature, which makes the videoludic medium stand out, may also support neoliberal discourses of self-responsibility by blaming players for the outcomes of predefined scenes and narratives. Video games, although not all of them, make use of ethical systems of a context to create an engaging and meaningful experience. Due to the medium's capacity to present choices to the audience it emphasizes their sense of control over the action. Thus, agency in videogames is commonly understood as the power to change and impact reality, and it comes from ideals such as control, freedom or responsibility, all linking it to the neoliberal values of risk-taking and individual accountability (Muriel \& Crawford 2018, p. 3). Video games create the illusion of the players' control over their actions, and more importantly, over the outcome of the story (Eichner, 2013). But every game is governed by a series of algorithms that create mechanics that allow but also restrict and determine the possible and the impossible, the doable and the undoable, the controllable and the uncontrollable. A game forces the players to abide to its already pre-set rules, norms, and conditions. Without hacking the game, the players' actual control over their actions is much more limited than regularly stated (Muriel \& Crawford 2018, p. 3). 
103 Loading... The Journal of the Canadian Game Studies Association

Vol 13(22): 89-108

http://loading.gamestudies.ca

The focus of this article has been to study how $A C: N L$ explores the medium of video games to create a challenging but pedagogically useful socialisation simulation. To construct that experience, $A C: N L$ uses different mechanics to modulate and alter the players' agency, and their sense of control over their actions, the world, and their neighbours. This paper has argued that $A C: N L$ 's engagement with the representation of contemporary society is a sceptical exploration and simulation of neoliberal and liquefied cultural landscapes (Allison, 2015). This paper has then built on previous and fruitful analyses on Animal Crossing games and its franchise and how they relate to capitalist concepts and values such as consumerism, materialism, commerce, and debt. This paper has further built on these analyses and extended the focus to the social and cultural repercussions of the material neoliberal world of $\mathrm{AC}$, and how this shapes the players' experiences of the game. Consequently, the interest of analysing the economic world of $A C: N L$ has to do with its impact and permeations into the social relationships and the interpersonal bounds the players might create, and how far they are able to do so.

Therefore, this article has focused on the mechanics and aesthetics (the process through which humans react to and make sense of the world) of $A C: N L$, as well as their interconnections. From this I have concluded that $A C: N L$ interrogates the neoliberal context from which it originates, centred not only on the materiality of late-stage capitalism, but on its metaphysical, ontological, and existential project. As Iida argues:

"capitalism here does not denote a narrowly conceived economic system, but a system that demands particular modes of social organization in accord with the existing modes of production: the corresponding social relations of production, specific legal and political frameworks, a social infrastructure, and a set of values and codes of behaviour"

(Iida, 2005, p. 253)

This is my main exploration of $A C: N L$, as it interrogates and presents options to the players within layers of suspicion and ambiguity. $A C: N L$ does not force the players to accept or resist the alluring and hegemonic neoliberal system it constructs. Its project is morally ambiguous and open. It is up to the players to decide, to act according to their ethics, or to explore possible worlds that, nonetheless, are very much tied to the one outside the game. What is then the message of $A C: N L$ ? That everything solid is melting into air? How would you, as a player, as a human, as a social agent dwell in that world? That is the main question of $A C: N L$, a reflexive challenge the players face every day in their real as well as this virtual world. 
104 Loading... The Journal of the Canadian Game Studies Association Vol 13(22): 89-108

http://loading.gamestudies.ca

\section{References}

Allison, A. (1994). Nightwork: Sexuality, Pleasure, and Corporate Masculinity in a Tokyo Hostess Club. Chicago: University of Chicago Press.

- - (2006). Millennial Monsters: Japanese Toys and the Global Imagination. Berkeley: University of California Press.

——. (2013). Precarious Japan. Durham: Duke University Press.

- - (2015). Discounted Life: Social Time in Relationless Japan. In Boundary, (2), pp. 129141.

Anable, A. (2018) Playing with Feelings: Video Games and Affect. Minnesota: University of Minnesota Press.

Andrejevic, M. (2009). Critical Media Studies 2.0: An Interactive Upgrade. In Interactions: Studies in Communication and Culture 1 (1), pp. 35-51.

Asad, T. (2007). On Suicide Bombing. New York: Columbia University Press. 
105 Loading... The Journal of the Canadian Game Studies Association

Vol 13(22): 89-108

http://loading.gamestudies.ca

Ash, J. (2012). Attention, Videogames and the Retentional Economies of Affective Amplification. In Theory, Culture and Society, 29(6), pp. 3-26.

Behrenshausen, B. G. (2013). The Active Audience, Again: Player-Centric Game Studies and the Problem of Binarism. In New Media \& Society, 15 (6), 872-889.

Berardi, F. (2009). The Soul at Work: From Alienation to Autonomy. Cambridge, MA: Semiotext(e).

Blackman, L. and Venn, C. (2010) Affect. In Body and Society 16 (1), pp. 7-28.

http://dx.doi.org.ezproxy.is.ed.ac.uk/10.1177/1357034X09354769

Bogost, I. 2007. Persuasive Games the Expressive Power of Videogames. Cambridge, Massachusetts: MIT.

Brown, A. and B. Berg Marklund. (2015). Animal Crossing: New Leaf and the Diversity of Horror in Video Games. In Proceedings of the 2015 Digra International Conference Diversity of Play: Games - Cultures - Identities.

Burkitt, I. (2014) Emotions and Social Relations. Los Angeles: SAGE.

Chiavacci, D. (2008). From Class Struggle to General Middle-Class Society to Divided Society: Societal Models of Inequality in Postwar Japan. In Social Science Japan Journal, 11.1, pp. 5-27.

Cromby, J. (2007). Towards a Psychology of Feeling. In International Journal of Critical Psychology, 21: pp. 94-118.

de Graaff, J. D. W. and T. H. Naylor. (2005). Affluenza: The All-Consuming Epidemic. San Francisco: Berrett Koehler.

Delamarre, F. M. (2011). Second Life as a digitally mediated third place: social capital in virtual world communities. In Crawford, G., Gosling, V. K. and Light, B. (Eds.) Online Gaming in Context: The Social and Cultural Significance of Online Games, pp. 236-248. London: Routledge.

Dewey, J. (1958). Experience and Nature. New York: Dover Publications.

de Graaff, J. D. W. and T. H. Naylor. (2005). Affluenza: The All-Consuming Epidemic. San Francisco: Berrett Koehler.

Doi, T. (2001). “Amae” no kōzō. Tokyo: Kōbundō.

Duncan, S. and Barrett, L.F. (2007). Affect is a Form of Cognition: A Neurobiological Analysis. In Cognition and Emotion, 21 (6), pp. 1184-211. 
106 Loading... The Journal of the Canadian Game Studies Association

Vol 13(22): 89-108

http://loading.gamestudies.ca

\section{http://dx.doi.org.ezproxy.is.ed.ac.uk/10.1080/02699930701437931}

Fortugno, N. (2009). Losing your Grip: Futility and Dramatic Necessity in Shadow of the Colossus. In D. Davidson (Ed.), Well Played 1.0. Videogames, Value and Meaning, (pp. 171186). Pitsburgh: ETC Press.

Freud, S. (1919). The Uncanny. Penguin: New York, 2003.

Giddens, A. (1991). Modernity and Self-identity: Self and Society in the Late Modern Age. Cambridge: Blackwell, 1991.

Gordon, A. (1993). Postwar Japan as History. Berkeley: University of California Press.

Hairston, M. (2010). A Cocoon with a View: Hikikomori, Otaku and Welcome to the NHK. In Mechademia 5, pp. 331-323.

Hughes, H. (2000). Familiarity of the Strange: Japan Gothic Tradition. In Criticism, 42(1), pp. 59-89.

Iida, Y. (2005). Rethinking Identity in Modern Japan: Nationalism as Aesthetics. London: Routledge.

Inoue, N. (2012). Media and New Religious Movements in Japan. Journal of Religion in Japan, 1(2), pp. 121-141.

Johnson, M. (2007). The Meaning of the Body: Aesthetics of Human Understanding. Chicago: University of Chicago Press.

Kim, J. (2014). "Interactivity, User-generated Content and Video Game: An Ethnographic Study of Animal Crossing: Wild World." In Continuum 28.3, pp. 357-70. Web.

Kingston, J. (2010). Critical issues in Contemporary Japan. Oxford: Blackwell.

Kotler, M., Sugawara, N. and Yamada, T. (2007). Chinese and Japanese Public Opinion: Searching for Moral Security. In Asian Perspective 31, pp. 93-125.

Malagon, A. et al. (2010). "Hikikomori": A New Diagnosis or a Syndrome Associated with a Psychiatric Diagnosis?. In International Journey of Social Psychiatry 56, pp. 558-559.

Massumi, B. (1995). The Autonomy of Affect. Cultural Critique, No. 31, pp. 83-109.

Brian, M (2002). Parables for the Virtual: Movement, Affect, Sensation. Durham: Duke University Press. 
107 Loading... The Journal of the Canadian Game Studies Association Vol 13(22): 89-108

http://loading.gamestudies.ca

Miyazaki, H. (2010). "The Temporality of No Hope." In C. Greenhouse (Ed.) Ethnographies of Neoliberalism, (pp. 238-66). Philadelphia: University of Pennsylvania Press.

Merleau-Ponty, M. (2012). Phenomenology of Perception. London: Routledge.

Muriel, D. and G. Crawford. (2018). Video Games and Agency in Contemporary Society. In Games and Culture, pp. 1-29.

Murray, J. (2016). Hamlet on the Holodeck: The Future of Narrative in Cyberspace. New York: The Free Press.

Nakane, Chie. (1967). Tate shakai no ningen kankei [Human Relations in a Vertical Society]. Tokyo: Kodansha.

Napier, S. (1996). The Fantastic in Modern Japanese Literature: The Subversion of Modernity. London: Routledge, 1996.

Ngai, S. (2005). Ugly Feelings, Cambridge: Harvard University Press, 2005.

- - (2012). Our Aesthetic Categories: Zany, Cute, Interesting. Cambridge: Harvard University Press, 2012.

NHK (2010). Muen shakai purojekuto. Muen shakai: muenshi sanman-nisennin no shōgeki [Relationless Society: The Shock of 32,000 Relationless Deaths]. Tokyo: Bungei shunjū.

Perkins, C. (2012). Flatness, depth and Kon Satoshi's ethics. In Journal of Japanese and Korean Cinema, 4(2), pp. 119-133.

Perron, B. (2009). The Survival Horror: The extended body genre. In B. Perron (Ed.), Horror Video Games: Essays on the Fusion of Fear and Play, (pp. 26-45). MacFarland and Company Inc: London.

Rosenwein, B. H. (2006). Emotional Communities in the Early Middle Ages. London: Cornell.

Rouse, R. (2009). Match Made in Hell: The inevitable success of the horror genre in video games. In B. Perron (Ed.), Horror Video Games: Essays on the Fusion of Fear and Play (pp. 15-25) MacFarland and Company Inc: London.

Seigworth, G.J. and Gregg, M. (2010). An Inventory of Shimmers. In Ed. Gregg, M. and G.J. Seigworth, (Eds.), The Affect Theory Reader, (pp. 1-25). Durham, NC: Duke University Press.

Sicart, M. 2009. The ethics of computer games. Cambridge, Mass.; London: MIT.

Stiegler, B. 2010. For a New Critique of Political Economy. Cambridge: Polity. 
108 Loading... The Journal of the Canadian Game Studies Association

Vol 13(22): 89-108

http://loading.gamestudies.ca

Teo, A. R. 2010. A New Form of Social Withdrawal in Japan: A Review of Hikikomori. In International Journey of Social Psychiatry 56, pp. 178-185.

Todd, K. H. L. (2010). Hikikomania: Existential Horror or National Malaise?. In Southeast Review of Asian Studies 33: pp. 135-147.

van Elferen, I. (2015) "Sonic Descents: Musical dark play in survival and psychological horror". In Ed. Mortensen, T.E., Linderoth, J. and Brown, A. (Eds.),), The Dark Side of Game Play (pp 226-241. Routledge: New York.

Zhang, P. (2008). Motivational Affordances: Fundamental Reasons for ICT Design and Use. Communications of the ACM, 51 (11), PP. 145-147.

Games Mentioned:

ConcernedApe. 2016. Stardew Valley. Chucklefish Games.

Nintendo. 2002. Animal Crossing. Nintendo

Nintendo. 2012. Animal Crossing: New Leaf. Nintendo 